\title{
ENRAIZAMENTO DE ESTACAS HERBÁCEAS DE DIFERENTES ESPÉCIES DE MARACUJAZEIRO ${ }^{1}$
}

\author{
GIVANILDO RONCATTO ${ }^{2}$, GERALDOCOSTANOGUEIRAFILHO ${ }^{3}$, CARLOS RUGGIERO $^{4}$, \\ JOÃOCARLOS DE OLIVEIRA ${ }^{4}$,ANTÔNIO BALDO GERALDO MARTINS ${ }^{4}$
}

RESUMO - O trabalho foi realizado na Área de Propagação de Fruteiras do Departamento de Produção Vegetal da Faculdade de Ciências Agrárias e Veterinárias, Universidade Estadual Paulista (FCAV/UNESP), em Jaboticabal-SP, com o objetivo de verificar a possibilidade de obtenção de mudas por estaquia de maracujá (Passiflora spp.), nas espécies comerciais $P$. edulis Sims f. flavicarpa Degener e $P$. alata Dryander, e nos porta-enxertos $P$. giberti N.E.Brown, P. nitida H.B.K. e P. setacea D.C. O experimento foi realizado no período de junho de 2000 a junho de 2001, em câmara de nebulização intermitente, em condições de telado (50\% de sombreamento). As estacas foram coletadas de plantas adultas, oriundas do Banco de Germoplasma Ativo (BAG) do Departamento de Produção Vegetal da FCAV/UNESP e de pomares comerciais, no caso a espécie $P$. edulis f. flavicarpa, coletando-se a parte intermediária de ramos em estádio de crescimento vegetativo, preparando-se estacas herbáceas com, aproximadamente, $15 \mathrm{~cm}$ de comprimento, três nós e duas folhas reduzidas ao meio, coletadas em junho e outubro de 2000, e abril de 2001. As estacas foram tratadas com ácido indolbutírico (IBA) nas concentrações de 500; 1.000 e 2.000 mg. $\mathrm{L}^{-1}$, por cinco segundos, e sem tratamento (testemunha), e plantadas em bandejas plásticas $(40 \times 30 \times 10 \mathrm{~cm})$, com vermiculita de textura média, por 60 dias. A percentagem de enraizamento foi maior na espécie $P$. edulis f. flavicarpa $(76,7 \%)$, na primavera. A $P$. giberti e a $P$. nitida enraizaram na primavera e no inverno, e a $P$. alata em todas as épocas estudadas. A $P$. setacea não enraizou. A sobrevivência, o número e o comprimento de raízes foram maiores na primavera.

Termos para Indexação: ácido indolbutírico, P. edulis, P. alata, P. nitida, P. giberti, P. setacea.

\section{ROOTING OF HERBACEOUS CUTTING OF DIFFERENT PASSION FRUIT PLANT SPECIES}

ABSTRACT - The present work was performed at the Fruit Growing Propagation Area of the Plant Production Departament of the Faculdade de Ciências Agrárias e Veterinárias, Universidade Estadual Paulista (FCAV/UNESP), with the objective of verifying the obtainment potencial of passion fruit seedlings by cutting propagation at Passiflora edulis Sims f. flavicarpa Degener and Passiflora alata Dryander commercial species, and at Passiflora giberti N.E.Brown, Passiflora nitida H.B.K. and Passiflora setacea D.C. rootstocks. The trial was conducted under greenhouse condition with $50 \%$ of shading and intermittent nebulization chamber conditions. The cuttings were collected from adult plants of the germoplasm bank of the Plant Production Departament of the FCAV/UNESP and others from commercial orchards, like P. edulis f. flavicarpa. The intermediate part of the last growth branches in the growth stage and herbaceous cuttings with $15 \mathrm{~cm}$, three nodes and two half leaves were colected on June and October, 2000 and April, 2001. The cuttings were treated with Indolebutyric Acid (IBA) in 500, 1000 e 2000mg. $\mathrm{L}^{-1}$ concentrations and without using IBA (control), and cultivated in plastic trays $(40 \times 30 \times 10 \mathrm{~cm})$ with vermiculite during 60 days. The rooting percentage was better for $P$. edulis f. flavicarpa in spring (October) with 76,7\% without using IBA (control). P. alata Dryander and P. nitida rooted in different seasons using 500 mg.L $\mathrm{L}^{-1}$ of IBA. P. giberti rooted in spring, but without using IBA. The number and lenght of roots was higher in October. The surviving rate, as well as dead cuttings was higher on June 2000. P. setacea did not root.

Index Terms: Indolebutyric Acid, P. edulis, P. alata, P. nitida, P. giberti, P. setacea

\section{INTRODUÇÃO}

O maracujazeiro (Passiflora spp.) é originário da América Tropical, compreendendo 150 espécies da família Passifloraceae utilizadas para consumo humano. O Brasil é o maior produtor mundial, apresentando, em 2006, uma produção de 615.196 toneladas, área de 44.363 hectares, onde se cultiva o maracujáamarelo (P. edulis Sims f. flavicarpa Degener) em cerca de 95\% dos plantios, e o maracujá-doce ( $P$. alata Dryander) contribui com 5\% da área de maracujazeiro no Brasil. Os Estados maiores produtores são Bahia, São Paulo, Sergipe, Espírito Santo, Pará, Ceará e Minas Gerais (SIDRA/IBGE, 2007).
A multiplicação do maracujazeiro em escala comercial é feita por sementes, embora as matrizes não sejam selecionadas adequadamente, e as mudas formadas não tenham um controle de qualidade, evidenciando as possibilidades de reprodução de plantas suscetíveis a doenças e pragas, baixa produtividade, frutos com menor valor comercial e redução da vida útil. Salientase também que a produção de mudas por semente pode não transmitir com fidelidade as características genéticas da plantamãe, dada a segregação genética que este tipo de propagação apresenta, gerando material heterogêneo e, muitas vezes, de menor qualidade (São José, 1991).

${ }^{1}$ (Trabalho 240-07). Recebido em: 04-10-2007. Aceito para publicação em: 05-08-2008.

${ }_{2}^{2}$ Pesquisador da Embrapa Acre. Rodovia BR 364 km 14, Zona Rural, Cep 69901180 Rio Branco-AC. E-mail: givanildo@cpafac.embrapa.br

${ }^{3}$ In memorian

${ }^{4}$ Professor Titular da Unesp/FCAV. Via de acesso Paulo Donato Castellane, s/n Cep 14884-900 Jaboticabal-SP. 
A propagação por estaquia possibilitará perpetuar e multiplicar as melhores plantas de características agronomicamente desejáveis, em áreas novas, como processo normal de propagação. Também, possibilitará a obtenção de clones dos melhores porta-enxertos para a execução da enxertia.

No entanto, os resultados são conflitantes, muitas vezes ficando abaixo das expectativas, principalmente naquelas espécies silvestres, como $P$. giberti N.E.Brown ou maracujá-deveado, P. nitida H.B.K. ou maracujá-do-mato e P. setacea D.C., necessitando de novos estudos para viabilizar a estaquia. As espécies silvestres estudadas, $P$. caerulea L., $P$. maliformis, $P$. incarnata e $P$. serrato digitata L., apresentaram até $60 \%$ de enraizamento (Meletti \& Nagai, 1992) e P. actinia H.B.K com 90\% (Koch et al., 1998). Nas comerciais, P. edulis, P. edulis f. flavicarpa e $P$. alata, os resultados são mais promissores e, segundo Meletti \& Nagai (1992), essas espécies tiveram $75 \%$ das estacas enraizadas. Já Graça (1990) e Salomão et al. (2002) conseguiram, respectivamente, 90 e $96 \%$ de enraizamento das estacas, no $P$. edulis f. flavicarpa.

O objetivo deste trabalho foi verificar a possibilidade de obtenção de mudas por estaquia, nas espécies comerciais de maracujazeiros, representadas pelo maracujá-amarelo e doce, e nas espécies silvestres com potencial para porta-enxerto $P$. giberti, P. nitida e P. setacea.

\section{MATERIAL E MÉTODOS}

A área experimental pertence ao Departamento de Produção Vegetal da Faculdade de Ciências Agrárias e Veterinárias, Universidade Estadual Paulista (FCAV/UNESP), Câmpus de Jaboticabal, cujas coordenadas geográficas são: latitude $21^{\circ} 17^{\prime} 05^{\prime \prime} \mathrm{S}$ e longitude $48^{\circ} 17^{\prime} 09^{\prime \prime} \mathrm{W}$, altitude de aproximadamente $590 \mathrm{~m}$. O clima da região, segundo classificação de Koppen, é do tipo Cwa, subtropical, relativamente seco no inverno, com chuvas no verão, apresentando temperatura média anual de $22^{\circ} \mathrm{C}$ e precipitação de $1.552 \mathrm{~mm}$.

O trabalho foi conduzido de junho de 2000 a junho de 2001 em câmara de nebulização intermitente sob telado (50\% de sombreamento). As matrizes das espécies $P$. alata, $P$. giberti, $P$. nitida e $P$. setacea pertencem ao Banco de Germoplasma Ativo (BAG), do Departamento de Produção Vegetal. As estacas de maracujá-amarelo (P. edulis f. flavicarpa) foram provenientes de pomares próximos, de propriedades rurais nos municípios de Jaboticabal-SP (aproximadamente 10km) e Taquaritinga-SP (aproximadamente $30 \mathrm{~km}$ ), pomares estes em estádio inicial de produção de frutos. Quanto à origem geográfica das demais espécies, a $P$. alata foi procedente de Jaboticabal-SP, Ribeirão Preto-SP e Valinhos-SP, a P. nitida acesso Amazonas, a P. giberti e a $P$. setacea acesso Cenargen.

Plantas-matrizes foram selecionadas em função da sanidade, vigor, produtividade e qualidade de frutos. Foram conduzidas no período de junho a agosto, e de outubro a dezembro de 2000, até o período de abril a junho de 2001, estacas herbáceas da porção mediana de ramos em estádio de crescimento vegetativo, com cerca de $15 \mathrm{~cm}$ de comprimento e $4 \mathrm{~mm}$ de diâmetro, com três nós e duas folhas reduzidas ao meio, corte em bisel na extremidade basal e perpendicular na parte apical.

As estacas foram tratadas com IBA (ácido indolbutírico) nas concentrações de $500 ; 1.000,2.000 \mathrm{mg} . \mathrm{L}^{-1}$ e sem tratamento (testemunha), por imersão da extremidade basal por 5 segundos. Foi preparada uma solução de IBA para $500 \mathrm{~mL}$ (na solução contendo $1.000 \mathrm{mg} . \mathrm{L}^{-1}$ ), dissolvendo-se $500 \mathrm{mg}$ da substância pura em $250 \mathrm{~mL}$ de álcool etílico, agitando-se bem e adicionando-se água destilada até completar o volume. Essa solução alcoólica a $50 \%$ é melhor para dissolver o IBA, pois, quando se usa uma quantidade muito pequena de álcool, pode ocorrer a precipitação do IBA ao se adicionar água destilada. Após, foram plantadas em bandejas plásticas perfuradas, de dimensões 40x30x10cm, contendo vermiculita de textura média. As estacas foram submetidas ao regime de irrigação por sistema de nebulização intermitente (45 segundos desligado e 15 segundos ligado). O tempo de permanência na câmara de nebulização foi de 60 dias, quando foram avaliadas a percentagem de estacas enraizadas, que consistiu na contagem das estacas que emitiram, pelo menos, uma raiz; percentagem de estacas sobreviventes, que consistiu na contagem das estacas que permaneciam verdes; o número e comprimento de raízes/estaca, sendo contadas as raízes formadas nas estacas em cada repetição e foram medidas as cinco raízes mais longas, obtendo-se o número e o comprimento médio de raízes/estaca/repetição.

O delineamento experimental utilizado foi o de blocos ao acaso, com três repetições e 20 estacas por parcela, em esquema fatorial $5 \times 4 \times 3$, sendo os fatores: espécies ( $P$. edulis f. flavicarpa, P. alata, $P$. nitida, $P$. giberti e $P$. setacea), concentrações de IBA $\left(0 ; 500 ; 1.000\right.$ e $\left.2.000 \mathrm{mg} . \mathrm{L}^{-1}\right)$ e épocas (junho e outubro de 2000, e abril de 2001). Os dados foram submetidos à análise de variância, utilizando-se, para o teste F nível de 5\% e $1 \%$ de probabilidade, executados no Sistema para Análises Estatísticas (ESTAT) do Pólo Computacional do Departamento de Ciências Exatas da FCAV/UNESP. As médias foram comparadas entre si, pelo teste de Tukey, a 5\% e 1\% de probabilidade. As variáveis percentagem de enraizamento e percentagem de sobrevivência foram transformadas por arco-seno $\sqrt{X+0,5 / 100}$, e o número e comprimento de raízes por arco-seno $\sqrt{X+0,5}$.

\section{RESULTADOS E DISCUSSÃO}

$\mathrm{Na}$ análise de variância, observa-se que houve significância para todos os fatores estudados, quanto à percentagem de enraizamento avaliada, além da interação entre os fatores (Tabela $1 ; 2$ e 3 ). No geral, a espécie P. giberti apresentou o melhor enraizamento, considerando as diferentes concentrações de IBA, nas épocas em estudo. O melhor enraizamento foi na primavera (outubro a dezembro), nas espécies estudadas, considerando as várias concentrações de IBA. O $P$. edulis f. flavicarpa apresentou melhor enraizamento na primavera, o $P$. giberti enraizou na primavera e no outono (abril a junho), o $P$. nitida enraizou na primavera e no inverno (junho a agosto) e o $P$. alata não diferiu em relação às épocas testadas.

$\mathrm{Na}$ Tabela 4, encontra-se a percentagem de enraizamento de estacas, nas diferentes espécies, épocas e concentrações de IBA. Observa-se que a percentagem de enraizamento variou em 
função da espécie, sendo que o maracujá-amarelo ( $P$. edulis f. flavicarpa) apresentou o melhor índice de enraizamento (76,7\%) na primavera e sem IBA (testemunha). Um fator que pode ter contribuído para este bom resultado é o maior crescimento dos ramos na primavera, onde substâncias são sintetizadas internamente, especialmente auxinas, fitormônios que estimulam o enraizamento das estacas (Lima, 2005). A ampla variabilidade das espécies também pode ter contribuído para a viabilidade do processo, através da seleção de indivíduos superiores em relação à estaquia (Braga et al., 2005).

Resultado semelhante foi obtido por Feichtinger Júnior (1985) em Jaboticabal-SP, ou seja, 80\% de enraizamento, em agosto, sem o uso de fitormônios, além do que, ao testar número de nós ou gemas nas estacas, observou maior percentagem de enraizamento com três nós, mesmo número utilizado neste experimento. Já Salomão et al. (2002), em Viçosa - MG, obtiveram maior percentagem de enraizamento (96\%) com 3 nós ou mais. Entretanto, os resultados encontrados por Almeida et al. (1991) e Graça (1990), também em Jaboticabal-SP, foram melhores, 89 e $90 \%$, respectivamente, quando utilizaram IBA a $2.000 \mathrm{mg} . \mathrm{L}^{-1}$. Também, Junqueira et al. (2001) alcançaram bons resultados, com 90\% de enraizamento, sendo que Oliveira et al. (2002) conseguiram $75 \%$ de enraizamento, com 3 nós.

O outono (abril a junho) e o inverno (junho a agosto) proporcionaram as menores médias de enraizamento ( $8 \%$ ) para o maracujá-amarelo. Isso foi constatado por Souza et al. (2006), que conseguiram apenas $40 \%$ de enraizamento nesta época do ano. Desta forma, pode-se dizer que a maior concentração de IBA não substituiu a baixa quantidade de auxina endógena sintetizada pela planta nestas épocas, impossibilitando enraizamento satisfatório, além de causar inibição do enraizamento; além disso, as baixas temperaturas ocorrentes nesse período, provavelmente, não favoreceram o enraizamento das estacas.

Feichtinger Júnior (1985) também constatou que o inverno não é favorável para o enraizamento do maracujá-amarelo e obteve apenas 30\% de enraizamento, enquanto Graça (1990) conseguiu $82,5 \%$ de enraizamento nesta época.

No maracujá-doce, obtiveram-se índices de enraizamento inferiores ao maracujá-amarelo, com percentagens próximas a $50 \%$ nas diferentes épocas testadas, baseando-se apenas na melhor concentração de IBA de determinada época, como mostrado na Tabela 4 . O enraizamento no inverno foi influenciado pelas doses de IBA, sendo que, com 500mg.L $\mathrm{L}^{-1}$, obteve-se $45 \%$, já na primavera o enraizamento foi de $53,3 \%$, com $1.000 \mathrm{mg} . \mathrm{L}^{-1}$. No outono, o enraizamento foi de $56,7 \%$, sem o uso de IBA, demonstrando que a capacidade de formar raízes nesta época é maior.

Meletti \& Nagai (1992) conseguiram 75\% de enraizamento de estacas, em Campinas-SP, com maracujá-doce, e Cereda \& Papa (1989) 75,5\%, em Botucatu-SP, considerando que trabalharam com 500mg. $\mathrm{L}^{-1}$ de IBA. Salomão et al. (2002) obtiveram $94 \%$ de enraizamento, em Viçosa-MG, sem uso de IBA. Silva et al. (2005) obtiveram excelente resultado com $99,2 \%$ de estacas enraizadas. Vale ressaltar que os autores obtiveram estes resultados na primavera (outubro a dezembro).
Quanto à $P$. nitida, obtive-se $40 \%$ de enraizamento no inverno, com IBA a 500mg.L $\mathrm{L}^{-1}$ e 36,7\% na primavera, também com 500mg. $\mathrm{L}^{-1}$ de IBA, resultado superior ao observado por Melo (1999), que foi de apenas 25\%, e semelhante ao de Paula et al. (2005), que conseguiram $46 \%$ de estacas enraizadas, a 2.000mg.L $\mathrm{L}^{-1}$ de IBA, no inverno. De acordo com Pereira et al. (1998), o enraizamento para esta espécie foi de $78 \%$ na primavera, a $2.000 \mathrm{mg} . \mathrm{L}^{-1}$ de IBA, nas condições de Jaboticabal-SP. Já Junqueira et al. (2002), Chaves et al. (2004) e Junqueira et al. (2006) obtiveram índice máximo de enraizamento (100\%), utilizando 500mg. $\mathrm{L}^{-1}$ de ANA, em Planaltina-DF, resultado bem superior ao obtido neste trabalho.

A espécie silvestre $P$. giberti apresentou índice de enraizamento mais elevado na primavera $(66,7 \%)$, embora também tenha $55 \%$ das estacas enraizadas no outono, sendo que o desempenho foi inferior na concentração de $2.000 \mathrm{mg} . \mathrm{L}^{-1} \mathrm{de}$ IBA, nestas épocas. Paula et al. (2005) também conseguiram bom desempenho nesta espécie, com $63,88 \%$ de estacas enraizadas, mas com uso de IBA a $2.000 \mathrm{mg} . \mathrm{L}^{-1}$, no inverno.

A espécie $P$. setacea foi a de pior desempenho, com apenas $5 \%$ de enraizamento no inverno. Braga et al. (2005) e Braga et al. (2006) obtiveram apenas 28,6\% de enraizamento de estacas e Paula et al. (2005), 46,73\%, nesta espécie. Em contrapartida, Junqueira et al. (2002) e Chaves et al. (2004) conseguiram ótimo desempenho com $83,3 \%$ de estacas enraizadas. O menor enraizamento pode ser explicado pelo seu alto grau de lignificação dos ramos, desde o estádio de crescimento vegetativo. Os primórdios radiculares não conseguem ultrapassar este tecido lignificado, não efetivando o enraizamento. Supõe-se que o corte da casca na base da estaca pode viabilizar o enraizamento.

A sobrevivência das estacas, o número e o comprimento de raízes foram maiores na primavera, devido às condições ambientais mais favoráveis, e à condição fisiológica das matrizes (Tabela 5; 6; 7 e 8).

TABELA 1- Análise de variância para a percentagem de enraizamento em estacas de maracujazeiro. Jaboticabal-SP, 2000 e 2001.

\begin{tabular}{lcccc}
\hline CAUSA DE & G.L. & S.Q. & Q.M. & F \\
VARIACA0 & & & & \\
\hline FATOR A & 4 & 16880,3674 & 4220,0918 & $56,7673^{* *}$ \\
FATOR B & 2 & 7604,5366 & 3802,2683 & $51,1469^{* *}$ \\
FATOR C & 3 & 2484,6605 & 828,2202 & $11,1410^{* *}$ \\
FATOR AXB & 8 & 18065,2414 & 2258,1552 & $30,3760^{* *}$ \\
FATOR AXC & 12 & 2832,8314 & 236,0693 & $3,1755^{* *}$ \\
FATOR BXC & 6 & 1531,5893 & 255,2649 & $3,4337 * *$ \\
FATOR AXBXC & 24 & 5874,3353 & 244,7640 & $3,2925 * *$ \\
\hline TRATAMENTOS & 59 & 55273,5618 & 936,8400 & \\
BLOCOS & 2 & 459,3782 & 229,6891 & $3,0897 *$ \\
RESÍDUO & 118 & 8772,1357 & 74,3401 & \\
\hline MÉDIA GERAL & 22,3827 & & & \\
DESVIO-PADRÃO & 8,6221 & & & \\
C.V. (\%) & 38,5211 & & & \\
\hline
\end{tabular}

* Significativo a $5 \%$ pelo teste de Tukey

** Significativo a $1 \%$ pelo teste de Tukey

A - Espécie

B - Época

C - Concentração de IBA 
TABELA 2- Percentagem de enraizamento das espécies em relação às épocas. Jaboticabal-SP, 2000 e 2001.

\begin{tabular}{|c|c|c|c|c|c|}
\hline & & Época & & & \\
\hline Espécie & Junho & Outubro & Abril & $\mathrm{F}$ & D.M.S. \\
\hline P. nitida & $29,33^{11} \mathrm{Aa}$ & $27,78 \mathrm{Ba}$ & $11,39 \mathrm{Cb}$ & $15,94^{* *}$ & 8,36 \\
\hline P. alata & $24,47 \mathrm{Aa}$ & $28,92 \mathrm{Ba}$ & $30,71 \mathrm{Ba}$ & $1,67^{\mathrm{NS}}$ & \\
\hline P. giberti & $12,39 \mathrm{Bb}$ & $45,92 \mathrm{Aa}$ & $42,39 \mathrm{Aa}$ & $54,80^{* *}$ & \\
\hline P. edulis & $13,19 \mathrm{Bb}$ & $51,01 \mathrm{Aa}$ & $4,05 \mathrm{Cc}$ & $100,02^{* *}$ & \\
\hline P. setacea & $6,08 \mathrm{Ba}$ & $4,05 \mathrm{Ca}$ & $4,05 \mathrm{Ca}$ & $0,22^{\mathrm{NS}}$ & \\
\hline$F$ & $14,63^{* *}$ & $54,97 * *$ & $47,92^{* *}$ & & \\
\hline D.M.S. & 9,76 & & & & \\
\hline C.V. $(\%)$ & 38,52 & & & & \\
\hline
\end{tabular}

TABELA 4- Percentagem de enraizamento de estacas herbáceas de cinco espécies de maracujazeiro, utilizando diferentes concentrações de IBA, em 3 estações. Jaboticabal-SP, 2001 e 2002.

\begin{tabular}{|c|c|c|c|c|c|c|c|c|c|c|c|c|}
\hline & \multicolumn{12}{|c|}{ Época } \\
\hline & \multicolumn{4}{|c|}{ Junho 2000} & \multicolumn{3}{|c|}{ Outubro 2000} & \multicolumn{5}{|c|}{ Abril 2001} \\
\hline & \multicolumn{12}{|c|}{ Concentrações de IBA (mg. $\left.\mathrm{L}^{-1}\right)$} \\
\hline P.edulis & $5,00^{*}$ & 8,33 & 5,00 & 5,00 & 76,66 & 53,33 & 43,33 & 63,33 & 0,00 & 0,00 & 0,00 & 0,00 \\
\hline P.alata & 11,66 & 45,00 & 16,66 & 8,33 & 10,00 & 49,33 & 53,33 & 5,00 & 56,66 & 36,66 & 8,33 & 11,66 \\
\hline P.giberti & 3,33 & 23,33 & 0,00 & 1,15 & 63,33 & 55,00 & 66,66 & 20,00 & 55,00 & 51,66 & 43,33 & 36,66 \\
\hline P.nitida & 30,00 & 40,00 & 15,00 & 18,33 & 5,00 & 36,66 & 21,66 & 31,66 & 10,00 & 3,33 & 6,66 & 0,00 \\
\hline P.setacea & 5,00 & 0,00 & 0,00 & 0,00 & 0,00 & 0,00 & 0,00 & 0,00 & 0,00 & 0,00 & 0,00 & 0,00 \\
\hline
\end{tabular}

* Média de 3 parcelas, dados não-transformados.

TABELA 5 -Comportamento das diferentes espécies, épocas e concentrações de IBA quanto à percentagem de enraizamento, sobrevivência, número e comprimento médio de raízes. Jaboticabal-SP, 2003.

\begin{tabular}{|c|c|c|c|c|}
\hline Espécie & \% Enraizamento & \% Sobrevivência $1 /$ & $\mathrm{N}^{0}$ Raízes & Compr. Raízes \\
\hline P. nitida & $22,83^{1 /} \mathrm{B}$ & $27,22 \mathrm{BC}$ & $2,54 \mathrm{C}$ & $1,84 \mathrm{~B}$ \\
\hline P. alata & $28,03 \mathrm{AB}$ & $33,96 \mathrm{AB}$ & $3,51 \mathrm{AB}$ & $2,58 \mathrm{~A}$ \\
\hline P. giberti & $33,57 \mathrm{~A}$ & $35,10 \mathrm{~A}$ & $3,90 \mathrm{~A}$ & $2,39 \mathrm{~A}$ \\
\hline P. edulis & $22,75 \mathrm{~B}$ & $23,54 \mathrm{C}$ & $2,77 \mathrm{BC}$ & $1,60 \mathrm{~B}$ \\
\hline P. setacea & $4,73 \mathrm{C}$ & $11,90 \mathrm{D}$ & $0,72 \mathrm{D}$ & $0,75 \mathrm{C}$ \\
\hline F & $56,77^{* *}$ & $29,09^{* *}$ & $25,65^{* *}$ & $39,11^{* *}$ \\
\hline D.M.S. & 5,63 & 6,81 & 0,95 & 0,45 \\
\hline Junho & $17,09 \mathrm{~B}$ & $23,20 \mathrm{~B}$ & $2,24 \mathrm{~B}$ & $1,34 \mathrm{~B}$ \\
\hline Outubro & $31,54 \mathrm{~A}$ & $36,17 \mathrm{~A}$ & $3,28 \mathrm{~A}$ & $2,17 \mathrm{~A}$ \\
\hline Abril & $18,52 \mathrm{~B}$ & $19,66 \mathrm{~B}$ & $2,54 \mathrm{~B}$ & $1,98 \mathrm{~A}$ \\
\hline F & $51,15^{* *}$ & $41,62^{* *}$ & $8,23 * *$ & $23,49^{* *}$ \\
\hline D.M.S. & 3,74 & 4,53 & 0,63 & 0,30 \\
\hline 0 & $23,88 \mathrm{AB}$ & $31,51 \mathrm{~A}$ & $2,08 \mathrm{~B}$ & $1,94 \mathrm{~A}$ \\
\hline 500 & $27,37 \mathrm{~A}$ & $31,66 \mathrm{~A}$ & $2,98 \mathrm{~A}$ & $1,86 \mathrm{~A}$ \\
\hline 1000 & $21,04 \mathrm{BC}$ & $22,44 \mathrm{~B}$ & $2,84 \mathrm{AB}$ & $1,79 \mathrm{~A}$ \\
\hline 2000 & $17,25 \mathrm{C}$ & $19,77 \mathrm{~B}$ & $2,86 \mathrm{AB}$ & $1,73 \mathrm{~A}$ \\
\hline F & $11,14 * *$ & $15,64^{* *}$ & $3,57^{*}$ & $0,78^{\mathrm{NS}}$ \\
\hline D.M.S. & 4,74 & 5,74 & 0,80 & 0,38 \\
\hline C.V. $(\%)$ & 38,52 & 39,60 & 54,20 & 37,94 \\
\hline
\end{tabular}
teste de Tukey a $5 \%$.
TABELA 3- Percentagem de enraizamento das espécies e das épocas em relação às concentrações de IBA. Jaboticabal-SP, 2000 e 2001.

\begin{tabular}{lcccccc}
\hline & \multicolumn{7}{c}{ Concentração de IBA } \\
\hline Espécie & 0 & 500 & 1000 & 2000 & $\mathrm{~F}$ & D.M.S. \\
\hline P. nitida & $21,32^{1 /} \mathrm{Ba}$ & $28,56 \mathrm{Ba}$ & $21,06 \mathrm{Ba}$ & $20,41 \mathrm{Aa}$ & $1,78^{\mathrm{NS}}$ & 10,61 \\
P. alata & $27,61 \mathrm{ABb}$ & $41,30 \mathrm{Aa}$ & $28,39 \mathrm{ABb}$ & $14,82 \mathrm{ABc}$ & $14,16^{* *}$ & \\
P. giberti & $37,21 \mathrm{Aa}$ & $40,81 \mathrm{Aa}$ & $32,49 \mathrm{ABb}$ & $23,75 \mathrm{Ab}$ & $6,59^{* *}$ & \\
P. edulis & $26,48 \mathrm{ABa}$ & $22,11 \mathrm{Ba}$ & $19,20 \mathrm{Ba}$ & $23,21 \mathrm{Aa}$ & $1,09^{\mathrm{NS}}$ & \\
P. setacea & $6,76 \mathrm{Ca}$ & $4,05 \mathrm{Ca}$ & $4,05 \mathrm{Ca}$ & $4,05 \mathrm{Ba}$ & $0,22^{\mathrm{NS}}$ & \\
\hline F & $15,07^{* *}$ & $28,67^{* *}$ & $14,44^{* *}$ & $8,11^{* *}$ & & \\
D.M.S. & 11,27 & & & & & \\
\hline Junho & $17,83 \mathrm{Bab}$ & $25,72 \mathrm{Ba}$ & $12,62 \mathrm{Bb}$ & $12,19 \mathrm{Bb}$ & $8,01^{* *}$ & 8,22 \\
Outubro & $29,00 \mathrm{Aab}$ & $36,23 \mathrm{Aa}$ & $35,11 \mathrm{Aa}$ & $25,81 \mathrm{Ab}$ & $4,97^{* *}$ & \\
Abril & $24,80 \mathrm{ABa}$ & $20,15 \mathrm{Ba}$ & $15,38 \mathrm{Bb}$ & $13,75 \mathrm{Bb}$ & $5,02^{* *}$ & \\
\hline F & $6,42^{* *}$ & $13,45^{* *}$ & $30,35^{* *}$ & $11,22^{* *}$ & & \\
D.M.S. & 7,48 & & & & & \\
C.V. (\%) & 28,52 & & & & & \\
\hline
\end{tabular}

${ }^{1 /}$ Médias seguidas pela mesma letra minúscula na horizontal, e maiúscula na vertical, não diferem entre si, pelo teste de Tukey a $1 \%$. . 
TABELA 7- Análise de variância para o comprimento médio de raízes em estacas de maracujazeiro. JaboticabalSP, 2000 e 2001.

\begin{tabular}{lcccc}
\multicolumn{5}{c}{ SP, 2000 e 2001. } \\
\cline { 1 - 5 } CAUSA DE & G.L. & S.Q. & Q.M. & $\mathrm{F}$ \\
VARIACAO & & & & \\
\hline FATOR A & 4 & 75,4282 & 18,8570 & $39,1122 * *$ \\
FATOR B & 2 & 22,6563 & 11,3282 & $23,4962^{* *}$ \\
FATOR C & 3 & 1,1314 & 0,3771 & $0,7822^{\mathrm{NS}}$ \\
FATOR AXB & 8 & 63,2855 & 7,9107 & $16,4079 * *$ \\
FATOR AXC & 12 & 4,5536 & 0,3795 & $0,7871^{\mathrm{NS}}$ \\
FATOR BXC & 6 & 5,0254 & 0,8376 & $1,7372^{\mathrm{NS}}$ \\
FATOR AXBXC & 24 & 24,7544 & 1,0314 & $2,13933^{* *}$ \\
\hline (TRATAMENTOS) & 59 & 196,8348 & 3,3362 & \\
BLOCOS & 2 & 0,2076 & 0,1038 & $0,2153^{\mathrm{NS}}$ \\
RESIDUO & 118 & 56,8909 & 0,4821 & \\
\hline MEDIA GERAL & 1,8299 & & & \\
DESVIO PADRAO & 0,6944 & & & \\
C.V. (\%) & 37,9449 & & & \\
\hline
\end{tabular}

** Significativo a $1 \%$, pelo teste de Tukey

Ns Não-Significativo

A - Espécie

B - Época

C - Concentração de IBA

TABELA 8 - Análise de variância para a percentagem de sobrevivência em estacas de maracujazeiro. Jaboticabal-SP, 2000 e 2001.

\begin{tabular}{lcccc}
\hline CAUSA DE & G.L. & S.Q. & Q.M. & F \\
VARIACAO & & 12670,3601 & 3167,5900 & $29,0984^{* *}$ \\
\hline FATOR A & 4 & 9060,7424 & 4530,3712 & $41,6174^{* *}$ \\
FATOR B & 2 & 5108,0548 & 1702,6849 & $15,6414^{* *}$ \\
FATOR C & 3 & 23072,3716 & 2884,0464 & $26,4937 * *$ \\
FATOR AXB & 8 & 3077,5233 & 256,4603 & $2,3559^{* *}$ \\
FATOR AXC & 12 & 1923,1107 & 320,5185 & $2,9444^{*}$ \\
FATOR BXC & 6 & 7175,8280 & 298,9928 & $2,7466^{* *}$ \\
FATOR AXBXC & 24 & 62087,9908 & 1052,3388 & \\
\hline TRATAMENTOS & 59 & 174,8291 & 174,9145 & $1,6068^{\text {NS }}$ \\
BLOCOS & 2 & 12845,2098 & 108,8577 & \\
RESIDUO & 118 & & & \\
\hline MEDIA GERAL & 26,3455 & & & \\
DESVIO PADRAO & 10,4335 & & & \\
C.V. (\%) & 39,6025 & & & \\
\hline
\end{tabular}

* Significativo a 5\%, pelo teste de Tukey

** Significativo a $1 \%$, pelo teste de Tukey

NS Não-Significativo

A - Espécie

B - Época

C - Concentração de IBA

\section{CONCLUSÕES}

1-O maracujazeiro-amarelo (Passiflora edulis f. flavicarpa) apresentou maior potencial para produção de mudas por enraizamento de estacas na primavera, sem uso de fitormônio.

2-O maracujá-doce ( $P$. alata) enraizou no outono, inverno e primavera. O $P$. giberti enraizou na primavera e no outono, na testemunha, e com $1.000 \mathrm{mg} . \mathrm{L}^{-1}$ de IBA. O P. nitida enraizou na primavera e no inverno, a 500mg. $\mathrm{L}^{-1}$ de IBA. O P. setacea não enraizou nas épocas estudadas.

3-A sobrevivência de estacas, o número e o comprimento de raízes foram maiores na primavera.

\section{REFERÊNCIAS}

ALMEIDA, L.P. de; BOARETTO, M.A.C.; SANTANA, R.G. de. Estaquia e comportamento de maracujazeiros (Passiflora edulis Sims f. flavicarpa Degener) propagados por via sexual e vegetativa. Revista Brasileira de Fruticultura, Jaboticabal, v.13, n.1, p.157-159, 1991.

BRAGA, M.F.; JUNQUEIRA, N.T.V.; FALEIRO, F.G.; BELLON, G.; JUNQUEIRA, K.P. Maracujá-doce: melhoramento genético e germoplasma. In: FALEIRO, F.G.; JUNQUEIRA, N.T.V.; BRAGA, M.F. (Ed.). Maracujá: germoplasma e melhoramento genético. Planaltina-DF: Embrapa Cerrados, 2005. p. 601-616.

BRAGA, M.F.; SANTOS, E.C. dos; JUNQUEIRA, N.T.V.; SOUSA, A.A.T.C de; FALEIRO, F.G.; JUNQUEIRA, K.P.; REZENDE, L.N. Estaquia em espécies silvestres do gênero Passiflora. In: REUNIÃO TÉCNICA DE PESQUISAS EM MARACUJAZEIRO, 5., 2005, Planaltina. Trabalhos apresentados... Planaltina: Embrapa Cerrados, 2005. p. 91-95.

BRAGA, M.F.; SANTOS, E.C. dos; JUNQUEIRA, N.T.V.; SOUSA, A.A.T.C de; FALEIRO, F.G.; REZENDE, L.N.; JUNQUEIRA, K.P. Enraizamento de estacas de três espécies silvestres de Passiflora. Revista Brasileira de Fruticultura, Jaboticabal, v.28, n.2, p.284288, 2006.

CEREDA, E.; PAPA, R.C.R. Enraizamento de estacas das espécies de maracujazeiro P. alata Dryand e Passiflora edulis Sims f. flavicarpa Degener sob nebulização. In: CONGRESSO BRASILEIRO DE FRUTICULTURA, 10., 1989, Fortaleza. Anais... p.375-378.

CHAVES, R. da C.; JUNQUEIRA, N.T.V; MANICA, I.; PEIXOTO, J.R.; PEREIRA, A.V; FIALHO, J. de F. Enxertia de maracujazeiroazedo em estacas herbáceas enraizadas de espécies de passifloras nativas. Revista Brasileira de Fruticultura, Jaboticabal, v.26, n.1,p.120-123, 2004.

FEICHTINGER JÚNIOR, W. Enraizamento de diferentes tipos de estacas enfolhadas de maracujazeiro (Passiflora edulis Sims f. flavicarpa Degener) em câmara de nebulização. 1985. 50 f. Monografia (Trabalho de Graduação em Agronomia) - Faculdade de Ciências Agrárias e Veterinárias, Universidade Estadual Paulista, Jaboticabal, 1985.

GRAÇA, J. Estudo sobre a propagação do maracujazeiro (Passiflora edulis Sims f. flavicarpa Degener) através de sementes e estacas. 1990. 92 f. Dissertação (Mestrado em Produção Vegetal) - Faculdade de Ciências Agrárias e Veterinárias, Universidade Estadual Paulista, Jaboticabal, 1990.

IBGE - Instituto Brasileiro de Geografia e Estatística. Produção Agrícola Municipal. Maracujá. Brasília: Ministério do 
Planejamento, Orçamento e Gestão, 2007. Disponível em: <http:/ /www.sidra.ibge.gov.br>. Acesso em: 19 dez. 2007.

JUNQUEIRA, N. T. V.; CHAVES, R. C.; MANICA, I.; PEIXOTO, J. R.; PEREIRA, A. V. E FIALHO, J. F. Propagação do maracujazeiro azedo por enxertia em estacas herbáceas enraizadas de espécies de passifloras nativas. Planaltina: Embrapa Cerrados, 2002. 15p. (Boletim de Pesquisa e Desenvolvimento, 39)

JUNQUEIRA, N.T.V.; MANICA, I.; CHAVES, R. da C.; LACERDA, C. S.; OLIVEIRA, J. A. de; FIALHO, J. de. F. Produção de mudas de maracujá-azedo por estaquia em bandejas. Planaltina: Embrapa Cerrados. 2001.3p. (Recomendação Técnica, 42).

JUNQUEIRA, N.T.V.; LAGE, D.A. da C.; BRAGA, M.F.; PEIXOTO, J.R.; BORGES, T.A.; ANDRADE, S.R.M. de Reação a doenças e produtividade de um clone de maracujazeiro-azedo propagado por estaquia e enxertia em estacas herbáceas de Passiflora silvestre. Revista Brasileira de Fruticultura, Jaboticabal, v.28, n.1, p.97-100, 2006.

KOCH, R.C.; BIASI, L.A.; ZANETTE, F.; POSSAMAI, J.C. Propagação vegetativa de Passiflora actinea por meio de estacas semilenhosas. In: CONGRESSO BRASILEIRO DE FRUTICULTURA, 15., 1998, Poços de Caldas. Anais... p.573.

LIMA, A. de A. Aspectos fitotécnicos: desafios da pesquisa. In: FALEIRO, F.G.; JUNQUEIRA, N.T.V.; BRAGA, M.F. (Ed.). Maracujá: germoplasma e melhoramento genético. PlanaltinaDF: Embrapa Cerrados, 2005. p. 643-677.

MELETTI, L.M.M.; NAGAI, V. Enraizamento de estacas de sete espécies de maracujazeiro (Passiflora spp). Revista Brasileira de Fruticultura, Jaboticabal, v.14, n.2, p.163-168, 1992.

MELO, A.L. de. Métodos de quebra de dormência, e de armazenamento de sementes, e aspectos de obtenção de mudas de maracujá suspiro (Passiflora nitida H.B.K.). 1999. 95f. Tese (Doutorado em Agronomia, Área de Produção Vegetal) Faculdade de Ciências Agrárias e Veterinárias, Universidade Estadual Paulista, Jaboticabal, 1999.
OLIVEIRA, J.A. de; JUNQUEIRA, N.T.V.; PEIXOTO, J.R.; PEREIRA, A.V. Efeito dos substratos artificiais no enraizamento e no desenvolvimento de estacas de maracujazeiro-azedo (Passiflora edulis Sims f. flavicarpa Deg). Revista Brasileira de Fruticultura, Jaboticabal, v.24, n.2, p.505-508, 2002.

PAULA, M. da S.; PEIXOTO, J.R.; FALEIRO, F.G.; BELLON, G.; JUNQUEIRA, K.P.; BRAGA, M.F.; JUNQUEIRA, N.T.V. Informações preliminares sobre enraizamento de estacas de espécies silvestres e comerciais de Passiflora. In: REUNIÃO TÉCNICA DE PESQUISAS EM MARACUJAZEIRO, 5., 2005, Cerrados. Trabalhos apresentados... Planaltina-DF: Embrapa Cerrados, 2005. p. 96-99.

PEREIRA, F.M.; OLIVEIRA, J.C.; NACHTIGAL, J.C. Propagação vegetativa do maracujá-suspiro (Passiflora nitida) por meio de estacas herbáceas. In: SIMPÓSIO BRASILEIRO SOBRE A CULTURA DO MARACUJAZEIRO, 5., 1998, Jaboticabal. Resumos... p.313.

SALOMÃO, L.C.C.; PEREIRA, W.E.; DUARTE, R.C.C.; SIQUEIRA, D.L.D. Propagação por estaquia dos maracujazeirosdoce (Passiflora alata Dryand.) e amarelo (P. edulis f. flavicarpa Deg.). Revista Brasileira de Fruticultura, Jaboticabal, v.24, n.1, p.163-167, 2002.

SÃO JOSÉ, A.R. Propagação do maracujazeiro. In: FEREIRA, F.R., VAZ, R.L. A cultura do maracujá no Brasil. Jaboticabal: FUNEP, 1991.p.25-41.

SILVA, F.M.; CORREA, L. de S.; BOLIANI, A.C.; SANTOS, P.C. dos. Enxertia de mesa de Passiflora edulis Sims f. flavicarpa Deg. sobre Passiflora alata Curtis, em ambiente de nebulização intermitente. Revista Brasileira de Fruticultura, Jaboticabal, v.27, n.1, p.98-101, 2005.

SOUZA, P.V.D. de; CARNIEL, E.; FOCHESATO, M.L. Efeito da composição do substrato no enraizamento de estacas de maracujazeiro-azedo. Revista Brasileira de Fruticultura, Jaboticabal, v.28, n.2, p.276-279, 2006. 